Научная статья /

Research Article

УДК 82I.I6I.I.0+82I.I3I.I.о

ББК $83.3(2 \mathrm{Poc}=\mathrm{Pyc}) 6+$

$83.3(4$ Ита $) 4$
ДАНТЕ И ЕГО ПОЭМА В ВОСПРИЯТИИ Б. ЗАЙЦЕВА

(C) 202I г. А.В. Топорова

Институт мировой литературы им. А.М. Горького

Российской академии наук,

Российский государственный гуманитарный университет, Москва, Россия

Дата поступления статьи: 25 мая 2020 г.

Дата одобрения рецензентами: о8 июля 2020 г.

Дата публикации: 25 июня 2021 г.

https://doi.org/IO.22455/250O-4247-2O2I-6-2-I84-I97

Аннотация: В настоящей работе анализируется последнее сочинение, написанное Б.К. Зайцевым в России накануне эмиграции, - статья «Данте и его поэма», посвященная «Божественной комедии». При беглом чтении она производит впечатление отрывочных рассуждений о Данте и его творчестве в целом. Вместе с тем ее суть проясняется при выявлении основных акцентов, расставляемых автором, и при включении ее в контекст всего творчества Б. Зайцева. Фокусами интереса писателя являются Данте как личность («история души») и «Божественная комедия» как плод его творческого гения. Б.К. Зайцев, еще до эмиграции утративший родину, отчаянно искал «истину», жизненную и творческую, и в этих поисках изгнанник и правдоискатель Данте выполнял роль его Вергилия в путешествии по неведомым и нередко враждебным пространствам. В такой перспективе «Божественная комедия» приобретает совершенно особое значение, она воспринимается как «нечто вроде Евангелия». Сопоставление этой статьи Б. Зайцева с его следующим произведением, написанным уже в эмиграции, - очерком «Преподобный Сергий Радонежский» - позволяет увидеть единую перспективу зайцевского творчества: связь истины и Истины, слова поэтического и Слова-Логоса. Данте и Сергий Радонежский изображены как светочи и ориентиры в «сумрачном лесу» жизни. Их жизненный опыт, представленный в контексте их непростых эпох, служит источником сил и утешения для Б. Зайцева, предлагая модели жизненного поведения, позволяющего из ужаса и мрака выбраться к свету и Истине.

ключевые слова: русско-итальянские литературные связи, «Божественная комедия» Данте Алигьери, поэтика Б. Зайцева, эмигрантская литература.

Информация об авторе: Анна Владимировна Топорова - доктор филологических наук, ведущий научный сотрудник, Институт мировой литературы им. А.М. Горького Российской академии наук, ул. Поварская, д. 25 а, І2Іо69 г. Москва, Россия; профессор, Российский государственный гуманитарный университет, ул. Чаянова, д. I5, І25047 г. Москва, Россия.

ORCID ID: https://orcid.org/oooo-0003-2669-7734

E-mail: anna.toporova@gmail.com

Для цитирования: Топорова А.В. Данте и его поэма в восприятии Б. Зайцева // Studia Litterarum. 202I. T. 6, № 2. C. I84-197. https://doi.org/IO.22455/2500-4247-202I-6-2-I84-I97 


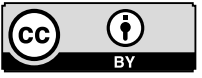

This is an open access article distributed under the Creative Commons Attribution 4.0 International (CC BY 4.0)

Studia Litterarum, vol. 6, no. 2, 202I

\section{DANTE AND HIS POEM AS PERCEIVED BY BORIS ZAITSEV}

(C) 202I. Anna V. Toporova

\author{
A.M. Gorky Institute of World Literature \\ of the Russian Academy of Sciences, \\ Russian State University for the Humanities, \\ Moscow, Russia \\ Received: May 25, 2020 \\ Approved after reviewing: July 08, 2020 \\ Date of publication: June 25, 202I
}

\begin{abstract}
The present article analyzes the last work written by Boris Zaitsev before emigrating from Russia: the article Dante and His Poem dedicated to Divine Comedy. At first glance, the article may seem to be a collection of sundry thoughts about Dante and his work. At the same time, its deeper meaning comes to the fore when one examines the main points made by the author and incorporates the article into his oeuvre as a whole. In the article, Zaitsev focuses on Dante as a human being ("history of the soul") and on Divine Comedy as a fruit of his creative genius. Having lost his native country even before emigrating from it, Zaitsev desperately began to search for the "truth" in both life and work. In this quest, the exile and truth-seeker Dante served as Zaitsev's Virgil in his voyage through unknown and often hostile territories. From this standpoint, Divine Comedy acquired a unique meaning for Zaitsev, who began to treat it as a Gospel of sorts. A comparison of this article with Zaitsev's next work, the essay Saint Sergius of Radonezh that he wrote in emigration, shows the unified perspective of the writer's work: the connection between truth and the Truth, between poetic word and the WordLogos. Dante and Saint Sergius are shown as beacons and waymarks in the "gloomy forest" of life. Their life experience, described in the context of their difficult times, served as a source of strength and solace for Zaitsev and offered models of existential behaviour that helped him to break out from horror and gloom towards light and Truth.
\end{abstract}

Keywords: Russian-Italian literary ties, Dante Alighieri’s Divine Comedy, Boris Zaitsev’s poetics, émigré literature.

Information about the author: Anna V. Toporova, DSc in Philology, Leading Research Fellow, I) A.M. Gorky Institute of World Literature of the Russian Academy of Sciences, Povarskaya 25 a, I2I069 Moscow, Russia; Professor, 2) Russian State University for the Humanities, Chayanova I5, I25047 Moscow, Russia.

ORCID ID: https://orcid.org/oooo-0003-2669-7734

E-mail: anna.toporova@gmail.com

For citation: Toporova, A.V. "Dante and His Poem as Perceived by Boris Zaitsev." Studia Litterarum, vol. 6, no. 2, 202I, pp. I84-I97. (In Russ.) https://doi.org/IO.22455/2500-4247-2O2I-6-2-I84-I97 
К 7оо-летию со смерти Данте

«Данте и его поэма» - таково название статьи, опубликованной Б.К. Зайцевым в г922 г. в Москве [І3]. Уже ближе к концу творческого пути писателя появится еще один вариант размышлений на эту тему, более обобщенный и краткий, под названием «Данте. Судьба» [г6]. Хорошо известен интерес Б. Зайцева к Италии, ее городам, культуре, великим персонажам [8, с. 267-269]. В течение пятнадцати лет он писал лирические очерки о городах Италии, вышедшие отдельным сборником в Берлине в г923 г. [I4]. Известно, что с г904 по г9г2 г. Б. Зайцев почти ежегодно бывал в Италии, часто вместе с П.П. Муратовым, по совету которого в І9І3 г. он взялся за перевод ритмической прозой дантовского «Ада»; этот труд был опубликован в Париже лишь в г96г г.

Таким образом, фигура Данте привлекала внимание Б. Зайцева на всем протяжении его жизни. Об этом сохранились и его собственные свидетельства. В письме к Н.Г. Елиной от г июня г967 г. он сообщает: «А Данте меня очень утешал. Я над ним пять лет в России работал (г9г3-I9I8), и два последних, трудных очень года он меня поддерживал. В г942 г. в Париже я весь перевод опять строку за строкой сличил и, когда немцы и англичане нас бомбардировали, спускался в подвал с женой и рукописью “Ада”. Место было подходящее. Дом дрожал, жена ко мне прижималась в нервной дрожи, и кругом были именно обитатели первых кругов “Ада”» [5, с. 276]. Эта же тема возникает и в письме от 3І января г969 г.: «Так что можно сказать, старик (Данте. - A.T.) прошел через всю мою жизнь. Среди грохота войн и революций поддерживал неукоснительно. Но и я берег любовь к нему и 
во время бомбардировки Парижа в подвал спускался с рукописью “Ада” ” [5, c. 277].

В июне I922 г. Б. Зайцев, переживший ужасы революции, потерю близких, арест, тяжелую болезнь, от которой он едва не умер, оказывается в эмиграции. Таким образом, статья «Данте и его поэма» была последним сочинением, написанным им в России.

Первое знакомство с этой статьей может вызвать некоторое недоумение: по сути дела, читатель не узнает ничего нового ни о самом Данте, ни о «Божественной комедии». Создается впечатление, что Б. Зайцев делает нечто вроде краткого обзора творчества Данте, будто взятого из какой-нибудь популярной истории итальянской литературы. Тогда возникает вопрос: а зачем он это делает? Какова цель написания и публикации этой статьи? Существует предположение, что статья была задумана как предисловие к зайцевскому переводу «Ада» [7]. Даже если это так, поставленный вопрос остается в силе, поскольку при беглом чтении статья предстает как достаточно общие и отрывочные рассуждения о Данте и его творчестве в целом. В любом случае опубликована она была как самостоятельное сочинение, на несколько десятилетий ранее самого перевода.

Обратимся к ее тексту и попытаемся определить акценты, которые расставляет Б. Зайцев. Прежде всего, очевидно его стремление не столько представить факты биографии Данте, сколько изобразить его характер, внутренний облик. Для Б. Зайцева Данте - живой человек, обладающий неповторимыми личностными особенностями, намного более важными, чем слова и действия, известные нам по многочисленным биографиям и исследованиям. Примечательно, что статья «Данте. Судьба» начинается словами: «Волшебный налет обращает фигуру Данте почти в легенду. Но все-таки Данте был, живой, настоящий. Только похожий на выходца из запредельного» [І6, с. 7]. Увидеть живого человека хотел Б. Зайцев и в статье 1922 г. Он неоднократно отмечает такие черты Данте, как суровость, гордость, молчаливость, одиночество, скрытую огненную силу. Приведем некоторые цитаты, относящиеся к разным этапам жизненного пути великого флорентийца:

«Данте был человек острых, сложных и сильных чувств - в те годы любовный мечтатель и мистик, со скрытно-огненным темпераментом; никак не видишь в нем сухого схоласта, сочиняющего по схемам» [3, с. 205]. 
«...все-таки Данте времен “Vita nuova” представляешь себе именно таким, каким изображен он (на фреске в Барджелло во Флоренции. - A.T.): юношей с тонким, острым и очаровательным профилем, юношей готическим, с сосредоточенным, задумчивым, почти печальным взглядом, скромным, уединенным и уже горделивым. Есть и подземные стихии в нем, но они еще не выбились наружу» [3, с. 206].

«Он молчалив, замкнут, суров» [3, с. 215].

«Кажется, в возрасте зрелом Данте и вообще был трудным человеком. Вероятно, изгнание закалило его гордость, от природы великую. <...> Современники говорят, что он был молчалив, угрюм, надменен» [3, с. 219].

И уже совсем в конце Зайцев приводит описание дантовской внешности, сделанное Боккаччо и добавляет от себя: «К старости он несколько сгорбился. Ходил медленно, с достоинством, одет был бедно, но во всем облике его была внушительность. Годы и испытания не согнули его. Но сломить такого человека было трудно...» [3, с. 219].

На протяжении всего рассказа о Данте Зайцев всматривается в него, изучает, пытается за внешними чертами распознать, выстроить «историю души» (это сочетание он также употребляет в статье [3, с. 2Іг]). И эта реконструкция одновременно научная и художественная. Она строится на исследовании биографических фактов и их логическом анализе, с одной стороны, и на интуитивном прозрении в глубины души - с другой. И здесь важным методом становится сопоставление собственного опыта с дантовским. Неоднократно упоминает Б. Зайцев об изгнании Данте и том влиянии, которое оно оказало на его жизнь: «...не выгнали бы его из Флоренции, не бродил бы он по Италии нищим поэтом и философом, учителем поэзии и высокомерным приживальщиком. Но тогда, возможно, иной была бы и “Божественная комедия" - мы не знаем, какой именно. Ибо слишком много гнева, тоски, скорбных раздумий дало ему изгнание» [3, с. 207].

Несколько ниже Б. Зайцев предполагает, что вряд ли Данте подолгу мог уживаться при дворах мелких правителей Италии: «Это их хлеб был ему горек и их лестницы трудны» [3, с. 2І8]. Несложно предположить, что судьбу изгнанника Б. Зайцев примеривал уже в это время и к себе. Исследовательница его творчества А. Шиляева обращает внимание на особенность Зайцева раскрывать в рассказе о других свой собственный облик [г2, с. 39]. Это замечание в полной мере можно отнести и к «дантовским» исследова- 
ниям Б. Зайцева. Значительно позже, в 1947 г., отмечая четверть века своего пребывания в эмиграции, Б. Зайцев выразится более определенно: «Таковы, кажется, все эмигранты, с давних времен. Так отец наш, Данте Алигиери Флорентинец, первый эмигрант Европы, вечерами выходил и молчаливо, подолгу смотрел на солнце заходящее - там Флоренция. А нам не удержаться на восток смотреть. Сколько смотрели, сколько дул оттуда ветер, летом ясность приносящий, зимой холод! Все казалось: а в конце концов ее увидишь. Что-то произойдет, так ли, иначе, восторжествует мир, свобода, человечность, можно будет и вернуться. Но Россия не приближалась. Ее жизнь шла, как ей назначено, путем безжалостным и беспощадным» [15].

В статье «Данте и его поэма» очевидны два фокуса авторского интереса: Данте как личность и «Божественная комедия» как плод его творческого гения. Б. Зайцев, еще до эмиграции утративший родину, привычный уклад жизни, близких людей (его племянник и приемный сын погибли в I92I г.), отчаянно искал «истину», жизненную и творческую, и в этих поисках изгнанник и правдоискатель Данте, можно сказать, выполнял роль его Вергилия в путешествии по неведомым и нередко враждебным пространствам.

В такой перспективе «Божественная комедия» приобретает совершенно особое значение, она воспринимается как «нечто вроде Евангелия» [3, с. 213]. Б. Зайцев лишь в очень общих чертах представляет читателю дантовскую поэму, повторяя хорошо известные рассуждения о буквальном и нравственно-аллегорическом смысле «Комедии», о путешествии человеческой души по загробному миру. Он даже перестает ссылаться на современных ему специалистов по Данте (Крауса, Дж. Скартаццини, автора известного трехтомника «Дантовская энциклопедия», Милан, I896-І905), мнения которых он приводит в связи с биографией поэта и его более ранними произведениями. Он ограничивается краткими и образными характеристиками; «научный» метод сменяется на поэтический. Б. Зайцев упоминает (не называя) о многочисленных исследованиях «Божественной комедии» в самых разнообразных ее аспектах и мельчайших деталях - «лингвистика, грамматика, синтаксис, метрика, характеристика метафор», статистика, объяснение темных мест и т. д. («кажется, не сосчитаны еще лишь запятые» [3, с. 2I3]) - и как бы отмежевывается от них, давая понять, что сути они не проясняют. 
Посмотрим, как Зайцев пытается определить эту суть:

«Мне всегда казалось, что главная художническая сила Комедии, главное ее очарование - само Слово» [3, с. 214].

«...по поводу “Ада”: при всей изобразительности деталей, в нем также слово, его своеобычность, сама манера произнесения этих удивительных стихов, превышает все» [3, с. 215].

«Слово и тон Комедии - единственны в мировой литературе. По силе и первозданности выражения можно их равнять лишь с Библией. Это не отнимает у Данте привкуса личного, того неповторимого, что есть одно из волшебств искусства» [3, с. 215].

«И в этой цельности нигде (как и в Библии) не встретишь и следа залощенности, середины. Никогда не скажешь: “Ни холоден, ни горяч, но тепел”. Все предельно» [3, с. 215].

Ядро этих характеристик - уподобление «Божественной комедии» Священному Писанию: дважды упоминается Библия, один раз Евангелие и один раз Слово с большой буквы. Совершенно очевидно, что призыв Данте в письме к Кан Гранде делла Скала комментировать его поэму в четырех смыслах, применимых ранее лишь к священным текстам, был воспринят и Б. Зайцевым, выявившим связь поэтического слова (с маленькой буквы) со Словом-Логосом (с большой буквы). Б. Зайцев предлагает видеть в загробном путешествии поэта путь самого Данте, путь всякого человека и путь всего человечества. И цель этого пути - спасение. Отмечает Б. Зайцев и гармонию «Божественной комедии», которую он определяет как «вольное, естественное сожительство непосредственно-художественного с религиозно-философским, политическим, церковным» [3, с. 2І7], в чем видит корень ее непреходящего успеха: «Потому-то разные люди с одинаковым почтением приближались и будут приближаться к ней: поэты, теологи, моралисты, историки средневековья, историки итальянского Ренессанса» [3, с. 217]. Здесь, на наш взгляд, также можно усмотреть скрытую параллель со Священным Писанием, обращенным к каждому.

Завершается статья словами о посмертной славе Данте и ее символах - лавровом венце и орле, которые сопутствуют великому флорентийцу на его многочисленных изображениях. Напомним, что «Данте и его поэма» были последним сочинением, написанным писателем в России. 
Первым же трудом в эмиграции стал очерк «Преподобный Сергий Радонежский», опубликованный в Париже в 1925 г. Остановимся кратко на нем и попытаемся ответить на вопрос, случайно или нет такое соседство.

В эмиграции Б. Зайцев приходит к глубокому переосмыслению своих прежних взглядов. Главной темой его творчества становится Святая Русь которую он ищет в русских подвижниках, в монастырях, в русских писателях (В.А. Жуковский, И.С. Тургенев, А.П. Чехов и др.). И первым опытом в этой области становится жизнеописание преподобного Сергия, «игумена земли русской».

Б. Зайцев использовал для работы агиографические и историографические труды, соединив в своем очерке черты как житийной, так и исторической литературы. Он опирался на «Житие» Епифания Премудрого (начало $\mathrm{XV}$ в.), но еще в большей степени на сочинение иеромонаха Никона, который в I885 г. составил своеобразный компендиум, используя информацию из житий и летописных источников. Вместе с тем использовал Б. Зайцев и исторические труды о преп. Сергии (В.О. Ключевского, Е.Е. Голубинского). Историографические отступления встречаются на протяжении всего зайцевского повествования, а в конце текста он помещает подробные исторические комментарии. Таким образом, он создает особый жанр, сочетающий в себе черты агиографической и исторической литературы, его называют по-разному - очерком, биографией, неожитием ${ }^{2}$. Рассмотрим основные особенности очерка «Преподобный Сергий Радонежский».

Почти все писавшие о преп. Сергии говорили о его «государственном масштабе» (это слова из письма И. Шмелёва к О.А. Бредиус-Субботиной; религиозный философ Иван Ильин также подчеркивал государственное значение преп. Сергия - «Белая идея», г926). Этот же аспект интересует и Б. Зайцева. Важна для него и идея национальной идентичности преп. Сергия. Этим объясняется проходящее через все произведение сопоставление Сергия с Франциском Ассизским. Но главное для Б. Зайцева - понять облик преп. Сергия, увидеть его личность, поэтому он не столько пишет житие, сколько описывает жизнь: «Присмотримся же кего жизни» [17, с. 152].

I Cp. его слова: «Для нас Россия осталась больше в снах, иногда в выражении глаз русских, в косичках русских девочек, в запахе полей августовских и, главнейшее, в облике России духа, - во Святой Руси» [9].

2 «Преподобный Сергий Радонежский» Б. Зайцева анализируется в целом ряде работ: [I4; $4 ; 15 ; 2 ; 16 ; \mathrm{II}]$. 
Б. Зайцев выделяет эту фразу. Он подчеркивает тем самым, что создает живой облик Сергия. Несмотря на множество агиографических и исторических отсылок, в очерке присутствует несомненная авторская линия: попытки проникнуть в суть личности великого святого.

Итак, в центре внимания писателя - живой человек (как и в случае с Данте). Б. Зайцев показывает формирование и развитие его личности, прослеживает, как из скромного мальчика Варфоломея вырастает монах Сергий, пустынник, молитвенник, а затем религиозный и политический деятель. Каждому этапу посвящена отдельная главка: «Отшельник», «Игумен», «Святой Сергий чудотворец и наставник», «Преподобный Сергий и церковь» и «Сергий и государство».

Отметим также, что, в отличие от житий, в очерке Б. Зайцева довольно мало рассказывается о чудесах, сотворенных Сергием, например, очень яркое чудо возглашения во чреве матери опущено. Об остальных повествуется приглушенно. Для Б. Зайцева важен в первую очередь человек, личность которого автор пытается понять. Отсюда - множество собственных размышлений и предположений о преп. Сергии, о мотивах его поступков, отсюда поэтический стиль как одно из средств передачи духа преп. Сергия (вспомним, что тот же прием имеет место и в статье «Данте и его поэма»).

Этим же объясняется и сравнение Сергия с Франциском Ассизским, с Феодосием Печерским, Антонием Печерским и другими святыми, в результате которого делаются выводы о том, что преп. Сергий не такой, как они. Описывая аскезу Сергия, его стремление в «выпрямлении души к единой вертикали» [I7, с. I6o], Б. Зайцев сравнивает ее с экстатичностью Франциска Ассизского и приходит к выводу, что юродство чуждо Сергию, в нем «не-надломленность, неэкстатичность» и «решительно ничего нет болезненного», он «умерен, прост, сдержан» [I7, с. I6I], в нем «дух первохристианской простоты и бедности» [17, с. I63]. Эта простота святости и есть суть образа Сергия. Рассказывая о событиях жизни Сергия, Б. Зайцев выступает в роли постороннего наблюдателя, которому не дано проникнуть в душу героя, понять его мысли и чувства. Личность преподобного Сергия раскрывается через его поступки, а не через изображение внутреннего мира.

Еще одна важная характеристика произведения Б. Зайцева заключается в том, что русская история является не просто фоном, на котором разворачивается жизнь святого, а, можно сказать, действующим лицом по- 
вествования; и в этом принципиальное отличие зайцевского сочинения от жития Епифания Премудрого. Кроме того, в предисловии к своему очерку Б. Зайцев, как и в случае с Данте, указывает на «связь времен»: «Автору казалось, что сейчас особенно уместен опыт - очень скромный - вновь, в меру сил, восстановить в памяти знающих и рассказать незнающим дела и жизнь великого святителя» [13, с. I52].

Б. Зайцев ставит актуальный и для его времени вопрос: как в отшельнике, в скромном игумене, а не политике, проявились силы противостояния врагу; ведь Сергий дал великому князю Дмитрию благословение на Куликовскую битву. Здесь снова проявляются характерные черты преподобного Сергия: «До сих пор Сергий был тихим отшельником, плотником, скромным игуменом и воспитателем, святым. Теперь стоял перед трудным делом: благословение на кровь... Сергий не особенно ценил печальные дела земли... Но не его стихия крайность. Если на трагической земле идет трагическое дело, он благословит ту сторону, которую считает правой. Он не за войну, но раз она случилась, за народ и за Россию, православных. Как наставник и утешитель, “Параклет” России, он не может оставаться безучастным» [I7, с. I87]. Размышляя об этом поступке Сергия, Б. Зайцев обращается и к событиям XX в. и пытается ответить на вопрос о сопротивлении злу силой. Вспомним, что и в очерке о Данте Б. Зайцев, хоть и не столь явно, также пытается нащупать параллели с собственной жизнью и эпохой.

Посмотрим теперь, как Б. Зайцев изображает преп. Сергия. В отличие от Епифания, занимающегося «плетением словес», Б. Зайцев пишет просто и поэтически. Он описывает преп. Сергия как «скромного монаха», «простого с виду»: «Как удивительно естественно и незаметно все в нем! <... Негромкий голос, тихие движения, лицо покойное, святого плотника великорусского. Такой он даже на иконе - через всю ее условность - образ невидного и обаятельного в задушевности своей пейзажа русского, русской души. В нем наши ржи и васильки, березы и зеркальность вод, ласточки и кресты, и несравнимое ни с чем благоухание России. Все - возведенное к предельной легкости, чистоте» [I7, с. I72]. Это, конечно, не житийный портрет, в нем подчеркиваются личные, а также национальные черты преп. Сергия. Немногочисленные эпитеты используются не столько для украшения, сколько для характеристики героя. Тот же прозрачный поэтичный стиль, а также использование природных образов, уже намечается и в ста- 
тье «Данте и его поэма», в первую очередь для характеристики «Комедии» (ср.: «В Чистилище можно любоваться таинственными камышами, голубовато-серебристым утром, росою, которой Вергилий омывает лицо Данте, обгорелое в Аду. <..> В Чистилище является природа: здесь море, скалы, удивительные луга, дивные деревья. Бледно-зеленоваты, туманно-золотисты краски его. <...> Рай весь прозрачен, как эфирные моря, пронизанные светом» [3, с. 2I4]).

Для изображения преп. Сергия Б. Зайцев часто прибегает к «световым» и «огненным» эпитетам: «светлые видения», «дивный свет», «небесный свет», «блистающие одежды», «легкий небесный пламень», «ослепительный свет», «друг легкого небесного огня», «свет, легкость, огонь его духа». Это позволяет сосредоточить внимание на духовном аспекте личности святого. Как мы помним, те же световые образы используются и в описании облика, внешнего и внутреннего, Данте.

Таким образом, и Данте, и преподобный Сергий Радонежский (которые были, кстати, почти современниками - I265-I32I и I3I4-I392 гг. соответственно) изображены Б. Зайцевым как светочи и ориентиры в «сумрачном лесу» жизни. Их жизненный опыт, представленный в контексте их непростых эпох, служит источником сил и утешения для Б. Зайцева, предлагая модели жизненного поведения, позволяющего из ужаса и мрака выбраться к свету и Истине. Что касается Данте, то именно как «поэта справедливости в самом широком смысле слова» воспринимала его русская культура: «Неукротимая свобода духа, чаяние братства, гражданская доблесть и жажда духовного преображения, мера скорби и мера ненависти, бытийственная философия и крестный путь через тернии к звездам - вот что было определяющим в “русском” Данте» [I, с. 193]. А последние слова очерка о преп. Сергии прямо указывают на его роль в жизни русского человека: «В тяжелые времена крови, насилия, свирепости, предательств, подлости - неземной облик Сергия утоляет и поддерживает. Не оставив по себе писаний, Сергий будто бы ничему не учит. Но он учит именно всем обликом своим: одним он утешение и освежение, другим - немой укор. Безмолвно Сергий учит самому простому: правде, прямоте, мужественности, труду, благоговению и вере» [17, с. 200].

Отметим в заключение еще одно сходство, сближающее этих двух великих людей. «Божественная комедия» завершается созерцанием Троицы, 
достижением цели длительного путешествия по загробному миру и по человеческой жизни одновременно. А преподобный Сергий создает монастырь Пресвятой Троицы, символа единства и любви, вечности.

\section{Список литературы}

\section{Исследования}

I Асоян А.А. «Почтите высочайшего поэта...» Судьба «Божественной комедии» Данте в России. М.: Книга, I990. 220 с.

2 Ветрова М.В. Агиографическое и историографическое в очерке Бориса Зайцева «Преподобный Сергий Радонежский» // Культура народов Причерноморья. 200I. № 23. C. I39-I47.

3 Данте: pro et contra: личность и наследие Данте в оценке русских мыслителей, писателей, исследователей: антология. СПб.: Изд-во Русской Христианской гуманитарной академии, 20II. 958 с.

4 Евдокимова Е.А. Личность преподобного Сергия Радонежского в прозе Бориса Зайцева // Древняя Русь: во времени, в личностях, в идеях: материалы научной конференции. Альманах. СПб., Казань, 2ог4. Вып. 2. С. І87-г9г.

5 Елина Н.Г. «В подвал спускался с рукописью “Ада”...» (Письма Б.К. Зайцева) // Иерусалимский журнал. Jerusalem literary review. 2000. № 4. С. 275-278.

6 Любомудров А.М. Книга Бориса Зайцева «Преподобный Сергий Радонежский» // Литература и история. Исторический процесс в творческом сознании русских писателей XVIII-XIX веков / под ред. Ю.В. Стенника. СПб.: Наука, I992. C. 263-279.

7 Прокопов Т. Русский «Ад» Бориса Зайцева // Иные берега. 20I4. № 4 (36). C. $129-\mathrm{I} 43$.

8 Русское присутствие в Италии в первой половине XX века. Энциклопедия / ред.сост. А. Д’Амелия, Д. Рицци. М.: Политическая энциклопедия, 2ог9. 863 с.

9 Синельникова Г.П. Неожитие Б. Зайцева «Преподобный Сергий Радонежский» // Культура и текст. 2005. № 9. С. I44-I52.

Iо Солнцева H.M. Святой Сергий Радонежский и литература XX века // Stephanos: мультиязычный научный журнал. 20I4. № 6. С. І2-24.

II Хатидже Б. Традиции древнерусских житий в прозе Б.К. Зайцева «Преподобный Сергий Радонежский» // Современная наука. Сер. Гуманитарные науки. 2017. № 4. C. 50-53.

I2 Шиляева А. Борис Зайцев и его беллетризованные биографии. Нью-Йорк: Волга, I97I. I75 c. 


\section{Источники}

I3 Зайцев Б.К. Данте и его поэма. М.: Вега, г922. 32 с.

I4 Зайщев Б.К. Италия. Берлин: Изд-во З.И. Гржебина, г923. 34 с.

I5 Зайцев Б.К. «Юбилей». Заметка о печальном юбилее // Русская мысль. 1947. 3 сент. № 22.

I6 Зайцев Б.К. Данте: судьба // Возрождение. г965. № I66 (октябрь). С. 7-II.

I7 Сергий Радонежский: Сб. / сост. В.А. Десятников. М.: Патриот, І99I. 540 с.

\section{References}

I Asoian, A.A. "Pochtite vysochaishego poeta..." Sud'ba "Bozhestvennoi komedii" Dante $v$ Rossii ["Honour the Supreme Poet..." The Fate of Dante's "Divine Comedy" in Russia]. Moscow, Kniga Publ., I990. 220 p. (In Russ.)

2 Vetrova, M.V. “Agiograficheskoe i istoriograficheskoe v ocherke Borisa Zaitseva 'Prepodobnyi Sergii Radonezhskii'." ["Hagiographic and Historiographic in Boris Zaitsev's Essay 'Saint Sergius of Radonezh'.'] Kul'tura narodov Prichernomor'ia, no. 23, 200I, pp. I39-I47. (In Russ.)

3 Dante: pro et contra: lichnost' i nasledie Dante v otsenke russkih myslitelei, pisatelei, issledovatelei: antologiia [Dante: pro et contra. Dante's Personality and Heritage as Seen by Russian Thinkers, Writers and Scholars. An Anthology]. St. Petersburg, Izdatel'stvo Russkoi Hristianskoi gumanitarnoi akademii Publ., 20II. 958 p. (In Russ.) Evdokimova, E.A. “Lichnost’ prepodobnogo Sergiia Radonezhskogo v proze Borisa Zaitseva” [“Saint Sergius of Radonezh's Personality in Boris Zaitsev's Prose”]. Drevniaia Rus': vo vremeni, v lichnostiah, v ideiakh: materialy nauchnoi konferentsii. Al'manakh [Ancient Russia: in Time, in Personalities, in Ideas: proceedings of a scientific conference. Almanac], issue 2. St. Petersburg, Kazan, 20I4, pp. I87-I9I. (In Russ.)

$5 \quad$ Elina, N.G. "'V podval spuskalsia s rukopis'iu 'Ada'...' (Pis'ma B.K. Zaitseva)” [“'I Went Down to the Basement with a Manuscript of 'Inferno'...' (B. Zaitsev's Letters)”]. Erusalimskii zhurnal. Jerusalem literary review, no. 4, 2000, pp. 275-278. (In Russ.) Liubomudrov, A.M. "Kniga Borisa Zaitseva 'Prepodobnyi Sergii Radonezhskii'.” [Boris Zaitsev's Book 'Saint Sergius of Radonezh'.”]. Stennik, Iu.V., editor. Literatura i istoriia. Istoricheskii protsess $v$ tvorcheskom soznanii russkikh pisatelei XVIII-XIX vekov [Literature and History. The Historical Process in the Creative Mind of Russian Writers of the $I 8^{\text {th }}-19^{\text {th }}$ Centuries]. St. Petersburg, Nauka Publ., I992, pp. 263-279. (In Russ.)

7 Prokopov, T. “Russkii ‘Ad' Borisa Zaitseva” [“Boris Zaitsev’s Russian 'Inferno’.”] Inye berega, no. 4 (36), 20I4, pp. I29-I43. (In Russ.)

8 D'Amelia, A., and D. Ricci, editors. Russkoe prisutstvie $v$ Italii v pervoi polovine $X X$ veka. Entsiklopediia [Russian Presence in Italy in the First Half of the $20^{\text {th }}$ Century: Encyclopedia]. Moscow, Politicheskaia entsiklopediia Publ., 20I9. 863 p. (In Russ.) 
9 Sinel'nikova, G.P. "Neozhitie B. Zaitseva 'Prepodobnyi Sergii Radonezhskii'.” [“B. Zaitsev's Neo-Legend 'Saint Sergius of Radonezh'.”]. Kul'tura i tekst, no. 9, 2005, pp. I44-I52. (In Russ.)

Io Solntseva, N.M. "Sviatoi Sergii Radonezhskii i literatura XX veka” ["St. Sergius of Radonezh and Literature of 20 Century”]. Stephanos: mul'tiiazychnyi nauchnyi zhurnal, no. 6, 20I4, pp. I2-24. (In Russ.)

II Hatidzhe, B. “Traditsii drevnerusskikh zhitii v proze B.K. Zaitseva 'Prepodobnyi Sergii Radonezhskii'." ["Traditions of the Ancient Living in Prose B.K. Zaitsev 'The Religious Sergey Radonezhsky'."]. Sovremennaia nauka. Ser. Gumanitarnye nauki, no. 4. 20I7, pp. 50-53. (In Russ.)

I2 Shiliaeva, A. Boris Zaitsev i ego belletrizovannye biografii [Boris Zaitsev and His Fictional Biographies]. New York, Volga Publ., I97I. I75 p. (In Russ.) 